\title{
Commercial and Technical Productization for Fact-Based Product Portfolio Management Over Lifecycle
}

\author{
Niko Lahtinen, Erno Mustonen, and Janne Harkonen ${ }^{(1)}$
}

\begin{abstract}
Increasing product variety and expanding commercial offering create a challenge for companies in terms of keeping their product portfolio profitable and managing it through the entire lifecycle of products. Effective productization and product portfolio management (PPM) practices, supported by product structure considerations, may hold a key for product profitability over lifecycle. This article examines the current practices and improvement possibilities in productization and PPM, including the targets and key performance indicators (KPI), by considering the product lines of a global engineering company. The analysis utilizes the previous literature, company interviews, and relevant company materials. The article demonstrates company difficulties, which are stemming from inadequate definition of productization and imperfect PPM targets and KPIs over the product lifecycle. An initial framework is formed to support more holistic productization over product lifecycle alongside creating suitable PPM targets and KPIs.
\end{abstract}

Index Terms-Key performance indicator, lifecycle management, product lifecycle, product management, product portfolio management, product structure, productization.

\section{INTRODUCTION}

$\mathbf{T}$ HERE is a growing trend toward increasing product variety, which is driven by many factors, such as customer requirements and different regional requirements [1], [2]. This has pushed companies to develop new products and product variants to the markets in an ever-quickening pace [3]. Moreover, developing new products to the portfolio is usually seen beneficial for companies, and thought as a mandatory process in securing companies' existence [4]. Particularly, the new product performance is discussed [5]. However, there are several negative side effects in increasing the number of products in the portfolio. These side effects have been recognized in the earlier literature and include, for example, the increased cannibalization of products [6], reduced operational performance of the company [7], and a possible increase in customer confusion [2]. Therefore, it should be very carefully analyzed what kind of products should be

Manuscript received November 5, 2018; revised February 28, 2019 and May 13, 2019; accepted July 11, 2019. Review of this manuscript was arranged by Department Editor A. Brem. (Corresponding author: Janne Harkonen.)

The authors are with the University of Oulu, 90014 Oulu, Finland (e-mail: niko.lahtinen92@gmail.com; erno.mustonen@oulu.fi; janne.harkonen @ oulu.fi).

Color versions of one or more of the figures in this article are available online at http://ieeexplore.ieee.org.

Digital Object Identifier 10.1109/TEM.2019.2932974 added to the portfolio and how the productization should be done, to create a competitive commercial offering and to satisfy the most important customer requirements cost efficiently.

Product portfolio management (PPM) seeks to tackle product management, and range of offering related challenges by aiming to optimize and allocate the scarce resources between the different projects to achieve the business's new product and technology objectives [8]. However, the approach offered by [8] does not address the challenges with the existing active products and their management, nor the wider lifecycle angle, as the focus is mainly on prioritizing the research and development (R\&D) projects. In fact, most of the earlier PPM literature focuses merely on the management of R\&D or new product development (NPD) projects [8]-[13], thus neglecting the product lifecycle aspect. [14] have listed some of the current challenges caused by this type of limited PPM perspective, but the topic is otherwise not well covered by the literature. The challenges include, for example, undefined product portfolios, lack of portfolio level business case thinking, unplanned product lifecycles, and inadequate reporting capabilities, thus leading toward portfolio explosion [14]. Overall, PPM should analyze and decide on company products based on facts, not intuition. The long-term growth and profitability of the companies are impacted by the right product portfolio decisions [9]. Understanding the profitability of individual products may enable a step toward fact-based PPM analysis. The fact-based analysis would enable better decisions on what products a company should sell, deliver, and care for, whereas company business processes define how. This may improve the PPM focus from mere early stages to wider lifecycle considerations. Hence, also the active phase of products and obligations after, should be considered as a part of the PPM decisions. Some scholars [15], and the work in [16]-[20] have presented PPM frameworks or models that somehow address the lifecycle aspect. The work in [15] also defines the commercial and technical productization as a precondition for a more holistic PPM and present frameworks to address the challenges [19], [20]. However, the utility and applicability of the recommended frameworks and productization are yet to be fully confirmed.

It is necessary to understand the company products, customers, and the costs, to gain understanding over product level profitability. The productization concept may provide the necessary systematics for this type of analysis. Productization refers to the systematization of the offering by focusing on the commercial and technical perspectives of products or services with the 
support of the product structure concept [21]-[26]. Productization according to commercial and technical portfolios provides a platform for product and related life-cycle considerations [26]-[28]. Productization may initially involve the technical and commercial modeling of the products by utilizing the product structure concept [27]-[29], whereas in the more operational stage, the focus should be primarily on the commercial side of the product structure once the basic logic exists [27], [28]. Adequate productization logic may also support the necessary product data, business process, and IT system considerations [30]. However, regardless of some initial studies existing, the practical evidence is lacking.

This article focuses on analyzing the applicability of the productization concept as the necessary systematics for PPM in an engineering company. The related challenges are also analyzed. As understanding product portfolio performance necessitates measuring, the relevant targets and key performance indicators (KPIs) are considered. The study approaches productization, in a real context, from the perspective introduced by [15], [20], and [21]. The study is built around three research questions, which guide the flow of the research process.

RQ1: How can productization be done commercially and technically to support effective product portfolio management over the product lifecycle, and what are the relevant targets and key performance indicators?

RQ2: What are the current challenges, and how should the commercial and technical productization be done to support PPM over lifecycle, including the relevant PPM targets and KPIs?

The research is carried out by the support of analyzing previous literature, and interviewing employees of an engineering company, as well as analyzing company internal documents and data systems.

The rest of the article is structured as follows. Section II presents the literature review on the concepts that relate to the topic of the article. First, productization is discussed as an underlying concept that applies product structure, one that provides systematics for managing products and the related lifecycles. The entire collection of company's products is then linked to the productization concept and product lifecycle by discussing product portfolio management. As fact-based management of products and the entire portfolio necessitates measuring, the PPM related targets and KPIs are discussed. The discussed concepts are combined in the literature synthesis to provide a level of context for a productization framework. Section III describes the research process and applied methodology. Section IV evaluates the current practices in the analyzed engineering company and creates a construction for productization over product lifecycle. An initial frame for fact-based analysis of company products is discussed. Section $\mathrm{V}$ concludes this article.

\section{LITERATURE REVIEW}

The literature review first delves into the current meaning and definition of productization to establish the basis for understanding the management of products and product portfolio, for the purpose of this article. After clarifying the concepts, the relevant aspects of PPM targets and KPIs for managing the performance of the products and product portfolio are discussed.

\section{A. Productization}

Productization can be defined in many ways, but the concept is not completely established and clear in the literature [20], [31], [32]. However, great efforts have been put in by Harkonen et al. [31], Suominen et al. [33], and Simula et al. [34], who have carried out comprehensive literature reviews on productization, aiming to map, describe, and clarify the concept. Productization is mostly interpreted as the process of transforming ideas or customer needs into a sellable product offering [31], [33], [35]. The productization process is also generally seen to consist of commercial and technical perspectives, and to integrate both perspectives to enable varying product considerations [31], [33], [34]. The related differences and difficulties of combining these two perspectives are noticed and addressed to some extent in the earlier literature [36], [37].

Harkonen et al. [15], [21] have presented an approach to productization, which utilizes a product structure concept to divide the product portfolio into commercial and technical sections, and to relevant levels. The product structure particularly allows to model interrelationships of the products' various components [38], but the commercial side is less studied. Product structure is seen to allow assessing modularity by looking at the hierarchical levels [39]. The aim of modularity should be maintaining the external variety required by customers and reducing the internal variety of within the company [40]. Also, product platforms relate to reducing internal variety as a common base of components. Product variants can be derived, and standard parts enable economies of scale [40], [41]. Product structure can also be used to illustrate all the information related to the product [42] and to help with forming data models and configuration tools [1], [43]. The major benefits of establishing a clear product structure for company offering, can be seen in the ability to unify the conception of the product [21], [26], [43] and to enhance the communication and reporting between different groups [21], [26], [44]. The productization with the product structure concept has been studied at least for manufactured products [15] and for service products [31], [45], but there are room for supporting studies.

\section{B. Product Portfolio Management Over Lifecycle}

Product portfolio can be defined as the collection of products offered by a particular organization [46]. The company product portfolio is usually divided to smaller entities, such as product lines [47] or product families [48], [49]. Some researchers also approach the product portfolio from the product lifecycle perspective and refer to R\&D or NPD portfolios [9], [13], [50]. However, the emphasis is mostly on the early lifecycle, and fewer authors cover the later lifecycle stages, such as the maintain phase that includes the active sales of products, or the part of product portfolio that includes products under warranty [20]. Neither are the companies' after sales product portfolios widely discussed from the perspective of managing the portfolio of products over the lifecycles. Murthy and Blischke [51] have, 
however, realized how commercial and technical issues tend to interact strongly in determining the product profitability over the lifecycle. Similarly, as product management focuses on managing an individual product, or a piece of business [52], the product portfolio management can be considered to operate at a more holistic level, and to consider a set of products or projects [8]. Cooper et al. [53] define PPM simply as the prioritization, and resource allocation process between company's R\&D projects but fails to cover the other lifecycle phases. In addition, PPM can be considered as the manifestation of the company's business strategy [9], [12]. Major part of the earlier PPM related studies merely focus on the management of R\&D or NPD portfolios [8], [9], [13], [50], [53], leaving the management of existing other portfolios poorly examined [20]. The importance of the ability to govern PPM is understood, but the focus has been on new products [54]. Some researchers connect the lifecycle management aspect into the PPM and emphasize its importance [20], [55], [56], but the literature can be considered as somewhat scarce in this respect.

\section{Product Portfolio Management Targets and Key Performance Indicators}

To manage something, one must be able to measure its performance [57]. Regarding PPM targets and KPIs, they can be divided into three focus areas of strategic fit, value maximization, and portfolio balance [19], [53], [58]. The strategic fit describes how well the spent resources are aligned with the company strategy, whereas the portfolio balance considers many dimensions such as the risk levels, available resources and number of projects in the portfolio [19], [53]. The value maximization refers to the maximization of financial value in the short, or long-term [53]. Each focus area should be addressed by the measurement methods, to achieve an optimal product portfolio [53]. The success and profitability have been considered for new products [59], [60]. However, the previous literature has mostly covered only the early parts of the lifecycle in this respect.

Even though the focus areas are recognized and discussed in the literature, there are still challenges in companies applying them in practice. For example, the strategic fit is not always clear, or paid attention to in companies [61], and the balance aspect is many times overlooked by having too many ongoing projects taking the limited resources [15], [50]. Moreover, the PPM targets, KPIs, and measurement methods overall are quite different in each organization, as the decision making environment consists of so many factors [62]. Nevertheless, when it comes to the best performing companies, they tend to utilize a wide set of KPIs and measurement methods and to put more weight on the strategic dimensions [9], [63], [64], whereas the worst-performing companies are relying more heavily on to the financial measures [65].

\section{Literature Synthesis}

Fig. 1 synthetizes the previous literature on productization, product portfolio management, and PPM targets and key performance indicators over product lifecycle stages. Productization links inherently to the product structure concept, allowing

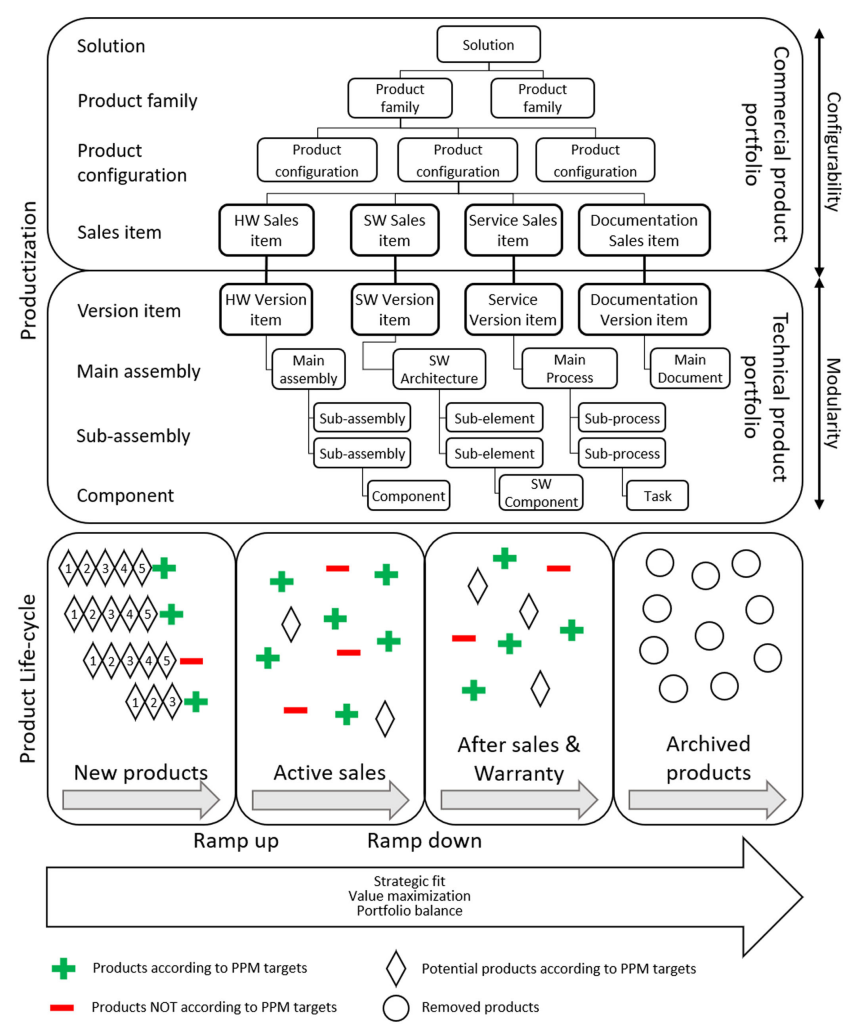

Fig. 1. Literature synthesis on productization, product portfolio management, and PPM targets and key performance indicators over lifecycle.

products to be considered from the commercial and technical perspectives. The product structure concept enables different types of products to be productized by using similar logic. All the items on the commercial side can be given a price as the costs are known. The commercial side is typically visible to customers. Depending on the company size and needs, the commercial side can contain different levels of hierarchy. Solution level is the highest level in the product structure, and can be a combination of many product families, or configurations of the different branches of product structure, or just single sales items. Product family is the collection of product configurations that are aimed toward the same customers or have the same technological platform. Product configuration consists of predesigned sales items, which are combined to create unique products to satisfy specific customer needs. Sales items, the lowest level of the commercial side, can be sold, delivered, and invoiced. Sales items can be hardware, software, service or documentation items. The configurability of products resides on the commercial side but is dependent on company operating model.

The technical side consists of the technical composition of products. Once the productization logic exists, the costs can be understood for each product version. Version items are created when some part of the original product is improved, often improvements involve reducing cost, or improving quality or performance. Main assembly is the highest level of assembly from the manufacturing viewpoint. Main assemblies are created from subassemblies, which are the lower tier of assemblies, consisting of the actual components from which the product 
is assembled. Component level is the lowest level in the product structure. The modularity of products resides on the technical side. Description of technical side is dependent on the product nature.

1) Finding: Product structure relates to productization and can be presented as a diagram to provide visualization and indicate hierarchical product decomposition. The technical side of product structure corresponds to bill of materials, and the commercial side is the corresponding commercial representation of the technical product. Consistent product structure enables effective referring to products and the constituting elements as data in company IT systems and benefits managing the product portfolio over lifecycle.

If a company has not productized its products according to the product structure concept, productization focus is first on the commercial and technical product structure. In the operational stage, once the basic productization logic has been defined, the focus is more on the commercial side of product structure, and primarily involves considerations over product configurations and sales items. Product configurations are primarily created based on existing sales items that have known costs. However, when desired product configurations are not possible via the existing sales items, the company can follow pre-defined rules to create new sales items to enable such configurations. By following a systematic logic for productization, companies' products are better manageable both individually, and as a part of company's product portfolio. The improved manageability also reaches over the product lifecycle.

Adequate productization logic may support the product data, business process, and IT system considerations alongside product lifecycle. Productization creates the foundations for a company to understand which of its products are profitable and which are not. The productization also enables understanding the number of items at each product structure level and allows managing them through the product lifecycle. Improved understanding over product composition together with the clear logic enables effective product portfolio, and product considerations over lifecycle stages. The sales price and cost of the product are the most crucial factors related to product level profitability calculations. A company should define the minimum the sales price for the product configurations and sales items. The minimum sales price can be defined once the costs are understood. It is the version item that links to the cost of each sold product version as it links to the technical composition. Therefore, the productization logic that includes both commercial and technical considerations appear necessary to support product level profitability considerations.

Product portfolio can be managed based on relevant targets and key performance indicators along the focus areas of strategic fit, value maximization, and portfolio balance. The lifecycle can be considered from the introduction of new products to the end of product life. Analyzing products in the active sales phase enables understanding how well the product portfolio corresponds to the set PPM targets, and whether the sold products are profitable. Actions can be taken based on PPM understanding. The same logic applies to the after-sales, or warranty portfolios. The data relating to products removed from the portfolio is archived for the minimum period required by the law.

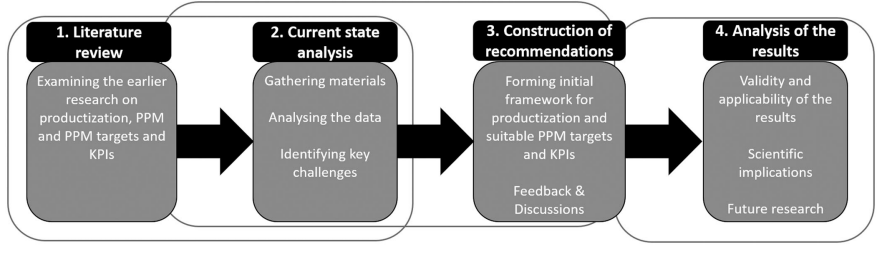

Fig. 2. Research process.

\section{RESEARCH PROCESS}

\section{A. Research Method}

This qualitative study is realized as a combination of a literature review, and interviewing 25 employees of an engineering company, as well as analyzing company internal documents and data systems. The study focuses on a single case of an engineering company, and the selected research approach follows an inductive logic. Case study research design was chosen given the need to gather rich data on the concept of productization [66], and its applicability. The research interest is somewhat pragmatic. In this type of study, researchers conclude the implications of their findings and aim at generalizable conclusions [67]. The approach, however risks providing insightful empirical generalizations, and little theory. The research process is presented in Fig. 2.

The study was initiated by carrying out a literature review to have the necessary understanding on the discussed topics, and to map the existing practices and knowledge, regarding productization, PPM, PPM targets and KPIs, and their interrelations. The literature review is carried out by conducting key word searches on article data bases to search for articles relevant for the topic in question. The used key words relate to and include several variations of the concepts of productization, product structure, PPM, and product lifecycle. Literature searches carried out for previous related purposes were also utilized. Identified documents and articles were carefully read to judge the suitability. The literature review was expected to partly aid in forming the interview questionnaire and to support the interview situations. The created interview structure is included in the Appendix.

The analyzed case was selected based on common interests on understanding the prerequisites of analyzing product level profitability, and the experience that better understanding over products, both commercially and technically might be needed. The opportunity to gain access also played a role.

Data collection includes interviews with company employees who hold necessary understanding, and with those responsible for the products and financial results. Besides the interviews, the empirical data contains supporting material that was gathered from company internal documents and company databases. The used material included product related bills of materials. The company provided access to their product structure and other product related documents. Access was also provided to PDM, ERP, and CRM. During the study an example product was productized both from the commercial perspective, and the technical perspective to allow discussing the studied matters with the company representatives by using their own context. 
TABLE I

INTERVIEWEE INFORMATION

\begin{tabular}{lc}
\hline Position in the company & Number of interviewees \\
\hline Project Manager & 3 \\
R\&D manager & 3 \\
Marketing Manager & 2 \\
Development Manager & 2 \\
Global Service Product Manager & 2 \\
Head of the Product Management & 1 \\
Global Sales Manager & 1 \\
Head of Global Sales Support & 1 \\
Global Product Management Manager & 1 \\
Global Product Engineering Manager & 1 \\
Product Marketing Manager & 1 \\
Global Product Line Manager & 1 \\
Technical Product Manager & 1 \\
Global Technology Manager & 1 \\
Senior Design Engineer & 1 \\
VP Sales & 1 \\
Production unit manager & 1 \\
Head of life-cycle management and support & 1
\end{tabular}

Observations were made by the interviewees. The collected material included statistics and information regarding productization and utilized PPM KPIs. All the material was used along with the interviews to evaluate the current practices in the company.

25 semistructured interviews [68] were carried out with predefined set of people who were seen to hold relevant knowledge on the studied issues, and to enable analyzing the current practices and situation. The interviewees were chosen, based on their experience on the studied topics, current position, and availability of access. Each interview was recorded to secure more precise analysis of the material. The selected group of employees included people from many different areas, due to the cross-functional nature of the studied issues. However, majority of the interviewees were managers involved in $R \& D$, product management, or sales and marketing. More specific list of the interviewee titles is included in Table I.

The coding involved the obtained data being used to create a description of the identified challenges and aiming to understand the applied product logic. The key activities were flagged. Any remarks were kept separate from the evidence. To avoid researcher bias, the information was reflected among colleagues to confirm the coding. Once the current way of structuring products was properly analyzed, and the main challenges recognized, an initial productization framework was constructed to allow systematics for product considerations over lifecycle, including relevant PPM KPIs. The applicability, utility, and validity of the proposals, were discussed with company representatives, who are responsible for the products and financial results. These discussions were arranged face-to-face among the primary interviewer and four people, first each individually to see possible differences in opinion, and later as a group. The titles of these people include: Technology Manager, Manager for Global Product Management, Development Manager, and Project Manager.
Comments by the responsible people were discussed among all the researchers to reflect the understanding. Minor corrections were made based on the feedback to the presented framework for productization.

Finally, the conclusions made based on the analysis and findings were compared against the existing literature and implications were concluded. The generalization is an important issue for case study research as the study can be relevant for a specific context, and not widely applicable regardless of the conclusions. Analytic generalization is one avenue to ensure generalization by using the previous literature as a template for comparing the results [66]. Also, fostering the development of several explanations for the phenomena is important. Triangulation embodies the use of mixture of data and researchers, wherein the researcher attempts to identify data that remains the same in different contexts, and different researchers focus on the same phenomenon [66]. To address the pitfalls of study of this nature, evidence is gathered from multiple sources. Overall, the research quality is important during the designing, conducting, and reporting of scientific research [67].

\section{B. Analyzed Company}

The analyzed company operates in multiple different business segments, providing high-technology products and solutions, and basic applications for several industries. Many of the sold products are very complex entities that include HW, SW, and service components. Complexity refers to complex product structure and technical complexity realized as a high number of product variations, technical assemblies, subassemblies, and components. The products can be customized and built according to customers' needs. The company is a global actor, serving customers and having employees in several different countries around the world. The company is organized into Business Segments, which are further segmented into Business Divisions (BDs). The BDs are divided into Business Lines (BLs), which have their own specific product offerings and responsibilities inside the BDs.

Due to the size of the analyzed company, this study focused on one $\mathrm{BD}$, which is currently the market leader in its field, offering machinery for better optimization and controllability of multiple sort of industrial processes and applications. The BLs within the analyzed Division have specific roles and responsibilities regarding the lifecycle phase of products. The BLs 1 and 2 provide new machinery for the processes, whereas BL 3 is responsible of the aftersales, care, and services for the sold products. Moreover, the BL 1 focuses on very complex, large, and mostly engineer-to-order type of machinery, whereas the BL 2 designs smaller and simpler devices for lighter processes. The BLs have developed very wide and extensive product portfolios, as the customers usually need quite many products simultaneously and they want to be able to purchase them all from the same provider. In addition to the large number of products, the requirements to respond to growing customer demands have steered the company to favor configurability in their products. Due to this, almost all the products in BL 1 and 2 are configurable, and even project type of orders are designed from the very beginning. A common 
customer of the BD either chooses a standard product variant, or selects among options, or requires a customized product, in which case the order is designed more specifically.

\section{RESULTS AND ANALYSIS}

The interviews and analyzed internal materials indicate that there are quite many challenges in the current productization, and the PPM targets and KPIs of the studied BD. The commercial and technical productization were both discovered to lack clear definitions and structure. In addition, the productization over lifecycle was perceived to be poorly understood and cooperated, thus creating problems in the lifecycle management of the product performance. Besides the inadequate productization, the lack of adequate PPM measurements over the product lifecycle was identified to threaten the profitability and the stability of the product portfolio in the long-term.

\section{A. Analysis of the Current Practices}

1) Commercial Productization: The analyzed BD was found to lack any defined commercial product structure, although some attempts toward one, seemed to exist. This fact was mirrored in the understanding and interpretations of various terms used in relation to the commercial offerings. For instance, the levels of the product structure were defined by various terms, and the relationships between products and the corresponding sales items were not commonly agreed. Some interviewees mistakenly considered product variants and options as the sales items from which the product is ultimately configured. Others interpreted the variants and options more as mere technical parts. One R\&D manager commented this as follows: "Product [X] is a variant, but I don't know a variant in relation to what. Technically it is a variant, but officially it is a new product. However, others may have a different opinion on that. For example, I don't know how product management sees it." Here, the undefined commercial product structure seemed to influence the monitoring of product variants and configurable options as they were not always identified or interpreted, as commercial sales items. Even in those scenarios, where the configurable items were perceived as sales items, their costs, volumes, or profits were not paid attention to. One statement by a product manager: "we do not have the time, resources or data available to keep track of every commercial item we have," indicated how they had not fully understood the significance of productization, and the implications of the lack of PPM. Simultaneously, the increasing number of new variants and options were commonly seen as a challenge, even though it was also deemed as a necessity to meet the emerging customer requirements.

Regarding the increasing variety and weak commercial productization, a concrete example was discovered among a group of customized products. These products were sold with a special option that allows minor customization to otherwise standard products. However, as the customization option was not considered as a sales item for the product, it was not paid that much attention to. Because of this negligence, the gross profit margins of the customized products were much smaller than for the standard product, even though the situation should have been the opposite. The customized products were seen to cause a lot of extra work in the organization whilst offering benefits for the customers. Due to the special nature of these products, they should have been providing more profits than average standard products. Interestingly, the poor performance of the sales item was only discovered during the interviews as the Product Managers did not originally view the sales item as an important commercial object.

2) Technical Productization: In relation to technical productization, the perceived challenges were related to technical complexity of the products and undefined technical structure. The products and solutions offered by the BLs are quite complex and technically multifunctional. As the well-defined technical product structure layers were missing, the number of technical components and modules has been growing. The situation is somewhat complicated by different R\&D teams designing components and modules, whilst clear company-wide guidelines for technical productization do not exist. The understanding and visibility of the relationships of the technical items seems to be at a poor level, thus encouraging the engineers to design new components and modules for new products, instead of utilizing existing technical items. The current use of modules is not systematic. Also, platform thinking is applied to certain extend but is not consistent. Linking the platforms with the commercial items causes great frustration, as the Global product engineering manager's comment expresses: "The number of people who can create a link between the technical platforms and the products is, well, there aren't many, and the way we are trying to visualise and open up this issue is totally useless... To our purchasing, this situation is a complete hell." Consequently, the R\&D teams cannot efficiently utilize the existing modules or components, as they are not easily available and reliable in any database. There also seems to be challenges in managing the product versioning, as versions are not addressed in the product structure. The smaller technical items, such as kits and components have practices for revisions and versions, but the actual products and sales items do not. This leads to a situation, in which the larger performance or quality upgrades are forced to be productized as new products or sales items, unnecessarily enlarging the portfolio. In the worst case, these upgrades are implemented as technical changes, ones that are not documented, further causing a great deal of trouble for the aftercare provider (BL 3). The aftercare provider needs the understanding of spare parts and services that are offered.

Due to the challenges, the number of actively maintained and purchased components has doubled in the past few years from some 15000 to 30000 . Simultaneously, there are multiple technical databases for similar products, and the number of technical changes in products is growing alarmingly. The most concrete examples are found among the daily employee actions, as they do not seem to be capable of coping with the number of engineering change notices and variability of components.

3) Productization Over the Product Life-Cycle: The productization over the company's defined product life-cycle ( $R \& D$, maintain, warranty, limited warranty, archive) was found to be unaligned, due to the missing product structure, but also due to the divided product ownerships between the BLs. As 
BL 1 and 2 are responsible of the product development and initial sales, they are likely to invent and add functionalities and options to their products to boost their revenues. However, as BL 3 is responsible of the spare parts and services, they are more willing to enhance the properties that aid in this dimension. Challenges arise, when the required monetary flows contradict the BLs' objectives. Many interviewees brought up this issue, as it was considered very difficult to add service capabilities to the products in the R\&D phase as it would increase the revenues of BL 3 at the expense of BL 1 and 2. In addition, the unaligned product structure was seen to further blur the impact of sales items in products, especially as BL 1 and 2 poorly consider the service sales items and service business possibilities.

It appears that productization over lifecycle is not thoroughly considered at a sufficient level within the BD. When a product is developed, the product lifecycle is not planned carefully enough and the profit-making mechanisms are not emphasized in the decision making. Also, the product lifecycle costs are not adequately considered, but the impacts are rather followed within certain time windows. As an insult to the injury, the reporting of sales and cost data of the spare parts and services is not at a level that would allow the more accurate estimation of product lifecycle impacts or product family levels. This finding was noticed during the interview with the Head of life-cycle management and support, as he stated: "we have absolutely no idea, how much a certain product family has contributed to the aftersales revenues." The fact that there is no even remotely reliable data on the products' later lifecycle costs and profits further emphases the importance of the more comprehensive productization over lifecycle.

4) Product Portfolio Management Targets and Key Performance Indicators: The PPM targets and KPIs were not well developed in the analyzed company as the overall art of PPM was still considered quite new. There were, however, ongoing efforts to enhance the company PPM. Majority of the targeted and measured matters seemed to be connected to financial performance of the products and product families, thus leaving the strategic fit and portfolio balance dimensions somewhat less targeted. Many of the monitored KPIs seemed to be linked to the early product phases, thus neglecting the lifecycle behavior of the product portfolio. The company did have diagrams and illustrations for multiple dimensions in PPM, such as the portfolio balance, portfolio risk-level, and the portfolio strategy. However, the interviewees pointed out that these dimensions were merely being monitored, without any real targets or KPIs. For example, the strategic allocation of R\&D resources did not have KPI for the spending of resources.

An example heard during several interviews indicated that some of the most strategically important projects were not getting their budgeted resources fulfilled. As one R\&D manager described the situation: "Although we have an on-going project that is seen as very important for renewing the portfolio, and to which should be given more focus and a budget, and the budget for the project actually exists. The problem is that we cannot spend the resources as much as the budget promised because urgent customer projects and commitments have the priority." However, this problem had not become visible enough, as there

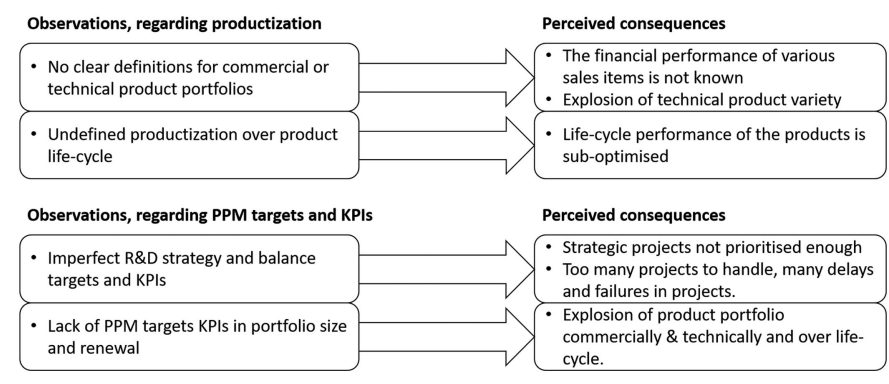

Fig. 3. Key observations and perceived challenges.

were no KPIs to reveal the asymmetry with the strategy and resourcing. The challenge of scarce resources and many demanding projects was not only reflected in the strategic sense, but in the portfolio balance dimension as well. According to the current KPIs, almost half of the projects in R\&D portfolio were being delayed and exceeding their cost targets. This is quite possibly a result of too many simultaneously ongoing projects, which the R\&D cannot handle with the current resourcing. Even so, there were no KPIs to keep track of the current burden of the R\&D department, money or time-wise, thus the knowledge about the actual capacity of the R\&D was being poorly addressed.

Regarding the targets and KPIs for the entire product portfolio, the results indicate that not much attention was directed toward the later product lifecycle stages. The company did not have any kind of relevant targets or measures for the size, or renewal rate of the portfolio. This can be seen as one reason for the dramatic increase in the number of commercial and technical items-no KPIs in place to illustrate the direction of the portfolio development. Fig. 3 synthesizes the recognized challenges regarding productization, and PPM targets and KPIs.

\section{B. Synthesis on Productization and PPM Targets and KPIs Over Lifecycle}

1) Initial Framework for Productization Over Product Lifecycle: It is recommended to define the product portfolio commercially and technically by establishing and implementing a clear product structure. The commercial product portfolio is to include a number of product structure levels to guide the reporting practices and interpretation of various items. These levels can include solution, product family, subproductfamily, product, and sales item levels. The Solution level would consist of product families and illustrate the possible solutions to be sold. The product families can be divided into subproduct families, which are aimed toward the needs of different customer segments within the product family's market segment. The subproduct families consist of products, which link to their sales item offerings, to match the specific customer requirements. The sales personnel select the most suitable product and configures it to match the defined customer needs. The actual product configuration is formed based on available sales items, which represent the different product options, variants and features that fulfil the set product functionality requirements. The sales items should be considered as hardware (HW), software (SW), service, or document items. These are the smallest items that are visible to 


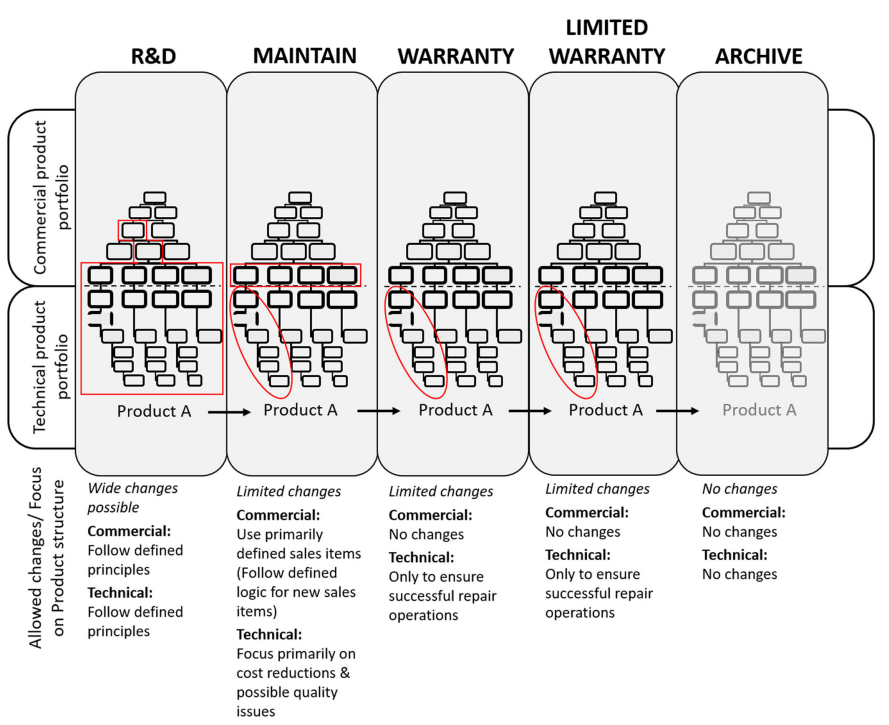

Fig. 4. Construction for productization over the product lifecycle.

the customer, and can still be invoiced, ordered, and delivered. Clearly defined sales item level should enhance the monitoring and understanding of the profitability and importance of the sales items, as well as help to narrow the offering to the most essential items.

The created technical product portfolio can consist of version item, cabinet element, main element, subelement, and platform component levels. The version item level would operate as a link to the commercial sales item level and enable tracking of version level changes in the corresponding $\mathrm{HW}, \mathrm{SW}$, service, and documentation products internally. This should reduce the need to create commercial items only to respond to small modifications, and simultaneously lessen the effort needed in the tracking and care services. Then again, the HW version item can be seen to consist of hierarchical structure of architectural elements, which can be modules or other kind of HW entities that fulfil a certain product functionality. All the elements are ultimately formed from their respective technological platforms and their components; thus, the lowest level of the technical side would represent the component assets. Distinctly defined product structure and categories for technical items, should make it easier for $\mathrm{R} \& \mathrm{D}$ department to locate similarities in product design, and favor design modularity.

The framework, involving the product structure should be integrated into the product lifecycle model of the company (see Fig. 4), and contain five horizontal portfolios based on the lifecycle phases. The productized offering moves along the lifecycle stages and the focus varies in each stage based on the focus. The profitability, costs, and required product management can hence, vary by the lifecycle phase, product, or business line. However, the sold sales items in each lifecycle phase can be considered to belong to the corresponding product families, subfamilies, and products and classified as either HW, SW, services, or documentation sales items. By unifying the understanding over the most profitable items that relate to each product and lifecycle phase, it should be possible to better optimize the offering over

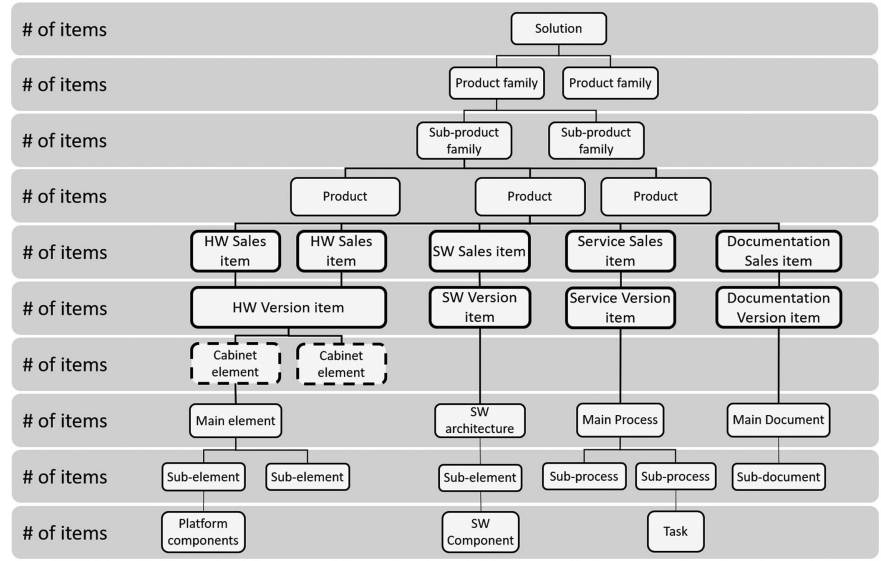

Fig. 5. PPM targets and KPIs for the size of commercial and technical portfolios.

lifecycle. This means, for example, creation of portfolio level business cases that consider the product families, products and their related sales items more holistically through the lifecycle. The focus on product structure along the lifecycle changes so that widest changes are possible during product development, whilst consistency is ensured by defined principles. After the $R \& D$ phase, the focus of product development is primarily on the technical side of the portfolio. Changes on the commercial side relate to creating new sales items. The focus narrows along the steps and is impacted by logic that relates to the mode of company operations. Certain company or industry specifics may exist.

2) PPM Targets and KPIs Over Lifecycle: The PPM targets and KPIs are aimed at addressing the challenges and consequences of deficient PPM. The R\&D resourcing must be aligned with the strategy by defining strategic portfolio categories and setting resourcing targets for each category. In addition, the fulfilment of resourcing should be kept in check by monitoring the actual amounts spent per category and reflecting it in the planning. This practice would illustrate clearly, whether the planned strategy is put into action or not. It is recommended to adjust the R\&D portfolio balancing by setting a target and KPI for the planned versus available resources in R\&D. Analyzing and presenting the current situation this way, should inform the management about the current situation and lessen the resource gap in $\mathrm{R} \& \mathrm{D}$.

What comes to the portfolio size and renewal, it is recommended to utilize the constructed productization framework while setting the targets and KPIs (see Fig. 5). The size of the commercial and technical product portfolios is to be monitored by tracking the number of items in each product structure level. The increases or decreases in these items would indicate the portfolio expansion or shrinkage and indicate the direction of the company's product offering. The direction set by the technical side, is to gradually lower the number of maintainable items. This can be done by decreasing the number of elements, element variants, and technology platform components, as well as increasing their commonality, reusability, and modularity. The decrease in technical complexity and portfolio size is reachable, 


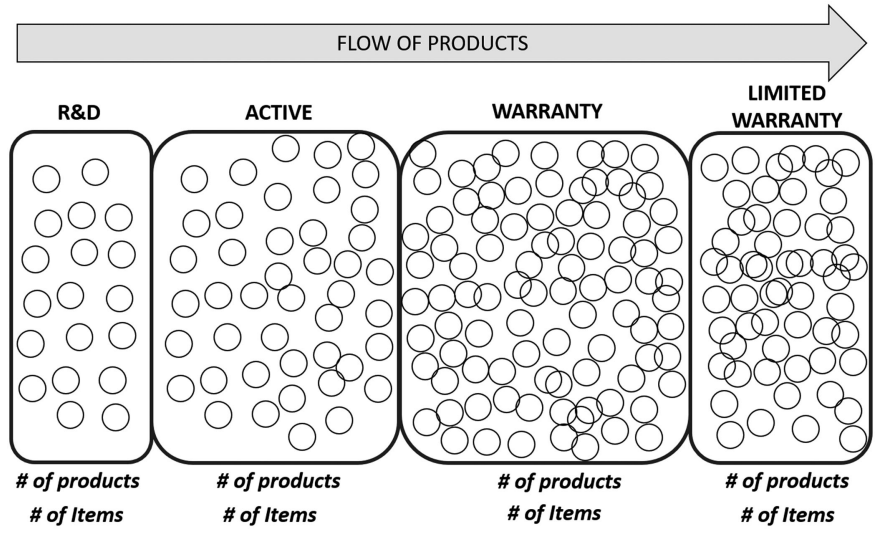

How many products are we having to manage in each phase now?

How many products are we managing in each phase in the future?

Fig. 6. PPM targets and KPIs for the portfolio size and renewal in the lifecycle dimension.

while retaining, or increasing the sales on the commercial side. This is enabled by the analysis of commercial portfolio and focus on development efforts on the most essential and profitable functionalities.

The lifecycle expansion and renewal rate of the portfolio is to be defined by monitoring the number of product variants in each life-cycle phase (see Fig. 6). The increase or reduction in the number of items in each lifecycle phase can indicate the renewal and expansion rate of the portfolio by showing how many products are added and removed from a certain life-cycle phase, in a given timeframe. This will also make the product lifecycle aspect more transparent by emphasizing the fact that every product and product variant will linger in the portfolio for a long-time and demand a certain amount of service and spare part capability even after product has been ramped down.

\section{DISCUSSION}

Company executives can have surprisingly modest understanding over their company's products or services. They may have varying understanding over what the company products are, and how many different products are being offered. Also, the product portfolio level analysis is modest, and focus has been on introducing new, rather than on products in the active, or later phases. The understanding over product level profitability in a certain lifecycle phase, or yet more over the entire lifecycle is lacking. The understanding over which products are in line with company strategy can also vary.

The question over how productization can be done to support effective product portfolio management over the product lifecycle can be approached by considering products structurally, both commercially and technically. Product structure logic acknowledging the commercial considerations, that is, what the customers are looking to buy, has been inadequate. Regardless of the nature of the product, physical, service, or other type, product configurations and sales items are relevant to be considered on the commercial side. The product configurations are combinations of defined sales items. The sales item level is the lowest level of commercial productization that customers can buy. Companies should have the ability to define minimum sales price for each possible configuration and sales item. The technical side of productization, also referred to as bills of materials, is better understood by companies. The highest level is the version item that signifies the product version and links to a sales item. The cost of each version item should be known. When any product changes take place, due to quality improvement, cost reductions, or so, a new version item is created and replaces the previous one. The technical composition of products is presented below the version item. The way the technical composition is described depends on the type of product. Components and assemblies are typical for physical products, processes for services, and so on. A product configuration can be a combination of sales items of different nature. The key to product level profitability lies between the axis of sales items and version items-the sales price and the relating costs. Should the productization logic be consistent, it should be possible to analyze profitability at different levels of the product composition. The above relates to managing the product portfolio vertically at different levels of product composition, commercially and technically.

The lifecycle aspect of PPM relates to the product structure horizontally through the focus varying over the course of the life-cycle. Focus is the widest during product development and narrows along the lifecycle stages. The lifecycle stage should hence govern how widely the product structure can be addressed. Once a product is ramped-up only small, or major enhancements to products should be allowed. Ideally only cost reductions and quality improvements would be allowed during the active phase of products, the "maintain" phase. Similarly, once a product is ramped-down and enters the "warranty" phase, only very minor enhancements to enable successful warranty should be allowed. This means even more narrow focus on the product structure. The specific allowed focus on changes along the product structure during each lifecycle stage should be defined by the company. One possible way of considering the life-cycle focus is the fit-form-function (FFF) rule. If FFF changes, a new lifecycle starts-If FFF does not change, in case of a new version, for example, the lifecycle continues.

The relevant PPM targets and key performance indicators can be drawn from company strategy, with attention on three focus areas of strategic fit, value maximization and portfolio balance. The relevant KPIs can be then defined company specifically based on the PPM targets. It should, however, be understood how the strategic focus will evolve along the lifecycle phases. The focus along the stages can involve, for example, PPM portfolio renewal by new products, business operations with aligned portfolio/enhancements for current products during the active phase "maintain," care for products during "warranty" phase, and storing product data based on legal requirements during "archive."

The current industry challenges that relate to PPM over lifecycle include the commercial and technical productization being 
discovered to lack clear definitions and structure. Particularly, the commercial perspective appears to be ignored in companies. Also, the basic understanding over PPM is lacking, particularly on focus beyond product development. The importance of PPM in the active phase of products, and the later phases has not been adequately understood before. Neither has the importance of consistent product structure been realized well enough. There is understanding how same consistent structural logic is necessary for PPM, regardless of the product type. Clear structural logic for product variants has been lacking, having caused challenges. In addition, the possibilities of measuring PPM have not been well understood. However, the product level profitability seems to be a good motivation for PPM considerations.

The missing adequate consistent product structure has hindered lifecycle considerations for PPM. Clear enough lifecycle logic has not existed for product level, and subproduct levels. In relation to PPM targets and KPIs, the target setting for PPM is newly understood, yet the understanding is not wide in companies. Company focus has been on wrong projects as prioritization has emphasized the early stages. Also, many of the existing KPIs ignore the active phases of products. The necessity of focusing on the active phase, and the later phases is only recently understood. PPM renewal has not been considered in the active, or the later phases, resulting in unnecessary portfolio explosion, which has resulted in many challenges.

The presented productization framework to acknowledge the product portfolio vertically at different levels of product structure, particularly the commercial considerations is found useful for practical PPM. The horizontal PPM and its benefits are understood as products are to transition from new product development stage, to active "maintain" phase, and to later "warranty" and "archive" phases in a planned manner. This requires active decision-making based on PPM targets and KPIs. PPM should hence decide on company's products now and in the future to enable future profitability.

Adequate commercial and technical productization together with a clear product structure logic can provide the necessary backbone for effective management of products and the entire product portfolio over lifecycle stages. Commercial and technical productization can support obtaining understanding over product profitability by providing the necessary structure for the analysis by enabling comparing sales of products and the corresponding cost information at different levels of product composition. This can enable manageable actions on products. Product portfolio thinking beyond the creation of new products, together with a clear and systematic productization logic, allows effective lifecycle analysis and actions.

Clear targets are required to meet company strategy in terms of products, and the entire product portfolio. Meaningful KPIs are needed to evaluate the success at reaching the product and PPM related targets. The focus areas of strategic fit, value maximization and portfolio balance appear relevant for PPM targets and KPIs. Productization, both commercially and technically, and relevant PPM targets and KPIs are all essential for effective product related considerations over the product lifecycle.

\section{A. Scientific Implications}

This article contributes by providing a realistic framework for understanding product profitability over lifecycle. Commercial and technical productization addresses the product structure vertically and forms the necessary frame of reference for systematic product level analysis. The article supports previous studies on productization [15], and [21]-[26] in emphasizing the role of commercial and technical perspectives and the use of product structure concept for PPM. New contribution lies in presenting real-life evidence. Indicating the relation of productization to enable vertical portfolio analysis according to numbers of items at each vertical level is a new contribution. Understanding the interaction of commercial and technical perspectives provides the practical means for determining the relevant aspects for product profitability, and hence [51] is supported in understanding the relevance of commercial and technical interaction for product profitability over lifecycle. This article provides foundations for understanding how PPM links to lifecycle through the horizontal product structure. PPM focus has previously limited to R\&D and NPD focus [8]. New contribution is provided by harnessing product structure logic horizontally to serve the needs of the active phase of products, the "maintain" phase, and the following "warranty and "archive" phases. The existence of products as data though the lifecycle is implied. The previous offering centric discussion on productization [31], [33], [35] is hence provided with the necessary practical support and extended to cover the lifecycle stages. Improving the current understanding on productization can be seen to support the stages of technology development [69] by indicating the necessity of considering the flow of products through the lifecycle. Commercial and technical productization provides new perspectives to the previous product structure discussion [38] by harnessing the component interrelations and logic to support product and PPM over lifecycle, also commercially. Support is provided for [39] in linking the modularity to the hierarchical levels of product structure but new contribution is provided by introducing the commercial perspective. For example, product variants are represented by different sales items in the productization concept. Support is provided for reducing internal variety within product families [40], [41] by providing some indications on the linkages to product modularity and use of platform thinking. Support is provided for [16]-[18] by providing new evidence to support productization and enhancing the link to horizontal lifecycle. The productization logic is seen as the necessary prerequisite to bridge the product data, business process, and IT system perspectives along the lifecycle. Being in line with [30], this article takes a step toward practical application. Systematic productization is understood to form an effective frame to product related information and support the increasing data perspective on products along digitalization [42].

This article supports the work that provides means for achieving new product and technology objectives via PPM [8], [13], [53], but extends the focus from the early stages to active stages and end-of life. Hence, [14] is supported in understanding the importance of PPM covering the lifecycle. The performance of the entire product range contributing to company success 
[54] is supported by indicating how productization forms the necessary foundations for managing the performance. New and complementary perspectives are provided to PPM frameworks to enable addressing the lifecycle aspect [15]-[20], [56] through productization. This article supports PPM targets and KPIs being possible to be drawn based focus areas of strategic fit, value maximization, and portfolio balance [19], [53], [58], but extends the focus to cover the active and later phases of products and indicates the focus to evolve. Support is also provided for studies that understand the necessity of being able to measure the performance to take managerial action [57]. New contribution to previous PPM discussion [8], [15] is provided by improving the understanding on productization vertically, and horizontally over the lifecycle by providing further evidence on deficiencies in this area.

\section{B. Managerial Implications}

Company decision makers may learn to appreciate the significance of analyzing product level profitability for active product portfolio decisions. The question over which products the company should develop, sell, deliver, care, and invoice is very significant to ensure success. Company executives may have surprisingly varying understanding over products, how many products the company has, and which of them are profitable. Decision makers can benefit of understanding the significance of consistent productization logic, both commercially and technically as an enabler for effective PPM. Profit can be calculated by comparing costs and the sales of products, whereas comparability necessitates consistency. PPM analysis can be carried vertically along products' structural levels. The managers can benefit of the understanding how the productization is the link to horizontal PPM analysis along the product lifecycle. Understanding how PPM targets and KPIs can be set based on strategy is also beneficial for company executives. Active PPM decisions may not strike as a priority when overall profitability is exceptionally good, but situations of smaller margins, competition, and increasing product variety may help to realize the significance. Companies' success can benefit greatly of the potential to better understand products and profitability over the lifecycle. Company decision and policy makers should consider the logic of commercial and technical productization and implement policies of following the logic should they wish to aim for managing their product portfolios effectively over lifecycle. Company staff also need to be trained to utilize the common productization logic and must be educated about the significance of product portfolio management and renewal over lifecycle, for successful business. The potential of further extending the productization logic from supporting PPM to link product data, business processes, and IT systems should not be ignored. Commercial and technical productization will benefit product, and PPM related considerations.

\section{Limitations and Future}

This article focuses on productization, PPM, and PPM targets and KPIs to support effective product portfolio management over lifecycle. The active understanding of product profitability is an underlying motivation, but no solution approaches for calculating product profitability is provided. The focus is more on the necessary foundations. The roles of data, processes, or information systems are neither covered in detail. Also, the way company supply chain logic may affect the productization logic is not analyzed. New evidence is, however, presented on the role of commercial and technical productization. The article has its limitations in terms of number of analyzed companies and interviewees. The proposed productization logic was accepted by responsible company representatives to be used in ongoing efforts to enable real-time analysis of products and the portfolio. Also, the focus was limited to certain product lines and a division. Hence, further studies are needed to include evidence from a variety of industries and companies, and to study the relation to established concepts such as modularization and use of platforms. Product master data and business process related data, and the role of different business processes and IT systems could also provide an interesting context to further analyze the role of productization. In addition, the potential real-time profitability feedback and analysis by utilizing PLM/PDM, CRM, ERP, and such, or via the means of a separate digital platform with suitable user interface might provide avenues of improving the use of existing data over the lifecycle with the support of productization. The concept of digital twin, the replica of physical assets, would also benefit of the analysis in the productization context.

\section{APPENDIX}

Interview structure

1. Product portfolio and productization

1.1. How do you understand a product?

1.2. Please describe the current product offering/product portfolio?

1.3. Is the current product offering structured by (please provide examples):

- Market segments?

- Customer segments?

- Product families?

- Global/regional products?

- Platforms?

- Solutions, product families, product configurations, sales items ... etc.

1.4. How is the product portfolio presented and defined (technically/commercially)?

- What are the identifiable product structure levels? (e.g., solution, product family, product configuration, sales item, version item, other?)

- What is the size (number of items) of the portfolio at each level?

- Where would you draw the line between commercial and technical product portfolio?

- From which database/systems can you find technical and commercial product portfolio?

1.5. During the past 3 years

- Has the total number of items in the product portfolio levels (solution, product family, 
configuration, version item, sales item, component ...) increased or decreased?

- What has been the root cause for this development?

1.6. Who owns the different items in:

- Commercial product portfolio?

- Technical product portfolio?

1.7. What is the current practice of adding/removing

- Product configurations

- Sales items

- Version items

- Modules/elements

- Components

1.8. What are the biggest challenges in productization (technical/commercial) currently?

2. Product portfolio management (PPM) targets and Key performance indicators (KPIs)

2.1. Why would PPM be important? How do you understand PPM?

2.2. What determines the PPM decisions?

- Competitor performance/actions?

- Company strategy?

- Customer satisfaction?

- Profit/value maximization?

- Organizational structures?

- Other?

2.3. What are the strategic targets of product portfolio management?

2.4. Product strategy: what kind of products do you have and what is their role?

2.5. Are the product lifecycle phases defined and planned when a new product is launched?

2.6. Product portfolio management (PPM) in new product development (NPD) phase:

- How are the products prioritized in NPD phase?

- What are the related targets and KPIs in NPD phase?

- What are the different tools utilized in prioritization process?

- What initiates product ramp-up process?

2.7. PPM in maintain phase

- How are the products and their enhancements being prioritized?

- What are the related targets and KPIs for maintain phase?

- What are the different tools utilized in prioritization process?

- What criteria initiates the ramp-down process?

2.8. PPM in warranty/service phase?

- How are the products and their enhancements being prioritized?

- What are the related targets and KPIs in warranty phase?

- What are the different tools utilized in prioritization process?

2.9. PPM in removal phase?

- How are the products being prioritized?
- What are the related targets and KPIs in removal phase?

- What are the different tools utilised in prioritization process?

- What is the criteria to remove a product?

2.10. What are the biggest challenges when setting targets and KPIs and utilizing tools/methods in PPM currently?

\section{REFERENCES}

[1] C. Forza and F. Salvador, Product Information Management for Mass Customization. London, U.K.: Springer, 2006.

[2] H. ElMaraghy et al., "Product variety management," CIRP Ann., Manuf. Technol., vol. 62, no. 2, pp. 629-652, 2013.

[3] H. Kropsu-Vehkapera, H. Haapasalo, O. Jaaskelainen, and K. Phusavat, "Product configuration management in ICT companies: The practitioners' perspective," Technol. Investment, vol. 2, no. 4, pp. 273-285, 2011.

[4] G. S. Lynn, K. D. Abel, W. S. Valentine, and R. C. Wright, "Key factors in increasing speed to market and improving new product success rates," Ind. Marketing Manage., vol. 28, no. 4, pp. 319-326, 1999.

[5] R. G. Cooper, "A process model for industrial new product development," IEEE Trans. Eng. Manage., vol. EM-30, no. 1, pp. 2-11, Feb. 1983.

[6] R. Srinivasan, S. Ramakrishnan, and S. E. Grasman, "Identifying the effects of cannibalization on the product portfolio," Marketing Intell. Planning, vol. 23, no. 4, pp. 359-371, 2005.

[7] X. Wan, P. T. Evers, and M. E. Dresner, "Too much of a good thing: The impact of product variety on operations and sales performance," J. Oper. Manage., vol. 30, no. 4, pp. 316-324, 2012.

[8] R. G. Cooper, S. J. Edgett, and E. J. Kleinschmidt, "New product portfolio management: Practices and performance," J. Product Innov. Manage., vol. 16 , no. 4 , pp. 333-351, 1999.

[9] J. H. Mikkola, "Portfolio management of R\&D projects: Implications for innovation management," Technovation, vol. 21, no. 7, pp. 423-435, 2000.

[10] R. G. Cooper, S. J. Edgett, and E. J. Kleinschmidt, "Portfolio management for new product development: Results of an industry practices study," $R \& D$ Manage., vol. 31, no. 4, pp. 361-380, 2001.

[11] R. G. Cooper, "How companies are reinventing their idea-to-launch methodologies," Res. Technol. Manage., vol. 52, no. 2, pp. 47-57, 2009.

[12] L. Kester, E. J. Hultink, and K. Lauche, "Portfolio decision-making genres," J. Eng. Technol. Manage., vol. 26, no. 4, pp. 327-341, 2009.

[13] R. C. McNally, S. S. Durmuşoğlu, and R. J. Calantone, "New product portfolio management decisions: Antecedents and consequences," J. Product Innov. Manage., vol. 30, no. 2, pp. 245-261, 2013.

[14] A. Tolonen, H. Kropsu-Vehkapera, and H. Haapasalo, "Product portfolio management - current challenges and preconditions," Int. J. Perform. Manage., vol. 4, pp. 69-90, 2014.

[15] A. Tolonen, J. Harkonen, and H. Haapasalo, "Product portfolio management-governance for commercial and technical portfolios over life-cycle," Technol. Investment, vol. 5, no. 4, pp. 173-183, 2014.

[16] T. Kohlborn, E. Fielt, A. Korthaus, and M. Rosemann, "Towards a service portfolio management framework," in Proc. 20th Australasian Conf. Inf. Syst., Melbourne, Vic, Australia, 2009, pp. 861-870.

[17] W. Bekkers, I. Van de Weerd, M. Spruit, and S. Brinkkemper, "A framework for process improvement in software product management," in Proc. Eur. Conf. Services Process Improvement, 2010, pp. 1-12.

[18] D. Jugend and S. L. Silva, "Product-portfolio management: A framework based on methods, organization, and strategy," Concurrent Eng., Res. Appl., vol. 22, no. 1, pp. 17-28, 2014.

[19] A. Tolonen, M. Shahmarichatghieh, J. Harkonen, and H. Haapasalo, "Product portfolio management-targets and key performance indicators for product portfolio renewal over life-cycle," Int. J. Prod. Econ., vol. 170, pp. $468-477,2015$.

[20] A. Tolonen, J. Harkonen, M. Verkasalo, and H. Haapasalo, "Product portfolio management process over horizontal and vertical portfolios,' Int. J. Product Life-Cycle Manage, vol. 8, no. 3, pp. 189-215, 2015.

[21] J. Harkonen, A. Tolonen, and H. Haapasalo, "Service productisation: Systematising and defining an offering," J. Service Manage., vol. 28, no. 5, pp. 936-971, 2017.

[22] I. Fazliu, "Product management and product portfolio management analysis in a case company," 2018. [Online]. Available: http://jultika.oulu.fi/ Record/nbnfioulu-201808312687 
[23] N. Lahtinen, "Commercial and technical productization in an engineering company," 2018. [Online]. Available: http://jultika.oulu.fi/Record/ nbnfioulu-201810032857

[24] L. Lushaj, "Productization, product management and product portfolio management practices in a case company," 2018. [Online]. Available: http://jultika.oulu.fi/Record/nbnfioulu-201810032869

[25] T. Kokkonen, "Business case sales planning concept for new products and product portfolio," 2017. [Online]. Available: http://jultika.oulu.fi/files/ nbnfioulu-201710112974.pdf

[26] A. Tolonen, "Product portfolio management over horizontal and vertical portfolios," Acta Universitatis Ouluensis, Univ. Oulu, 2016. [Online]. Available: http://jultika.oulu.fi/files/isbn9789526212678.pdf

[27] J. Harkonen, A. Tolonen, and H. Haapasalo, "Modelling of manufacturing services and processes for effective productisation," in Proc. 20th Int. Working Seminar Prod. Econ., Innsbruck, Austria, vol. 3, 2018, pp. $145-164$.

[28] J. Harkonen, A. Tolonen, and H. Haapasalo, "Modelling of construction products and services for effective productisation," Management, vol. 13, no. 4, pp. 335-353, 2018.

[29] A. Tolonen, J. Harkonen, H. Haapasalo, and H. Hannila, "Performance management of the manufacturing services product portfolio," in Proc. 20th Int. Working Seminar Prod. Econ., Innsbruck, Austria, vol. 3, 2018, pp. 417-432.

[30] R. Silvola, A. Tolonen, J. Harkonen, H. Haapasalo, and T. Mannisto, "Defining one product data for a product," Int. J. Bus. Inf. Syst., vol. 30, no. 4, pp. 489-520, 2019.

[31] J. Harkonen, H. Haapasalo, and K. Hanninen, "Productisation: A review and research agenda," Int. J. Prod. Econ., vol. 164, pp. 65-82, 2015.

[32] L. Leoni, "Servitization and productization: Two faces of the same coin?" in Proc. Eur. Assoc. Res. Services, Copenhagen, Denmark, B1-2, 2015, pp. 1-18.

[33] A. Suominen, J. Kantola, and A. Tuominen, "Reviewing and defining productization," in Proc. 20th Annu. Conf. Int. Soc. Prof. Innov. Manage., Vienna, Austria, 2009, pp. 63-85.

[34] H. Simula, T. Lehtimaki, and J. Salo, "Re-thinking the product: From innovative technology to productized offering," in Proc. 19th Int. Soc. Prof. Innov. Manage. Conf., Tours, France, 2008, pp. 1-13.

[35] E. Flamholtz, "Managing organizational transitions: Implications for corporate and human resource management," Eur. Manage. J., vol. 13, no. 1, pp. 39-51, 1995.

[36] F. J. Erens and H. C. Wortmann, Generic Product Modeling for Mass Customization, Implementation Road Map. Ann Arbor, MI, USA, 1996.

[37] J. Buijs, "Modelling product innovation processes, from linear logic to circular chaos," Creativity Innov. Manage., vol. 12, no. 2, pp. 76-93, 2003.

[38] V. K. Janardanan, M. Adithan, and P. Radhakrishnan, "Collaborative product structure management for assembly modeling," Comput. Ind., vol. 59, no. 8, pp. 820-832, 2008.

[39] F. Salvador, "Toward a product system modularity construct: Literature review and reconceptualization," IEEE Trans. Eng. Manage., vol. 54, no. 2, pp. 219-240, May 2007.

[40] D. Krause, G. Beckmann, S. Eilmus, N. Gebhardt, H. Jonas, and R. Rettberg, "Integrated development of modular product families: A methods toolkit," in Advances in Product Family and Product Platform DesignMethods \& Applications. New York, NY, USA: Springer, 2013, pp. 245269.

[41] J. R. Jiao, T. W. Simpson, and Z. Siddique, "Product family design and platform-based product development: A state-of-the-art review," J. Intell. Manuf., vol. 18, no. 1, pp. 5-29, 2007.

[42] A. Saaksvuori and A. Immonen, Product Life-Cycle Management, 3rd ed. Berlin, Germany: Springer, 2008.

[43] H. Kropsu-Vehkapera and H. Haapasalo, "Defining product data for different stakeholders," J. Comput. Inf. Syst., vol. 52, no. 2, pp. 61-72, 2011.

[44] H. Kropsu-Vehkapera, "Enhancing understanding of company-wide product data management in ICT companies," Acta Universitatis Ouluensis, Univ. Oulu, Oulu, Finland, 2012. [Online]. Available: http://jultika.oulu. fi/files/isbn9789514297984.pdf

[45] S. Kuula, H. Haapasalo, and A. Tolonen, "Cost-efficient co-creation of knowledge intensive business services," Service Bus., vol. 12, no. 4, pp. 779-808, 2018.
[46] M. A. Jacobs and M. Swink, "Product portfolio architectural complexity and operational performance: Incorporating the roles of learning and fixed assets," J. Oper. Manage., vol. 29, no. 7, pp. 677-691, 2011.

[47] P. Kotler and K. L. Keller, Marketing Management, 15th ed., Boston, MA, USA: Pearson, 2016

[48] X. Du, J. Jiao, and M. M. Tseng, "Architecture of product family: Fundamentals and methodology," Concurrent Eng., vol. 9, no. 4, pp. 309-325, 2001.

[49] K. B. Kahn, The PDMA Handbook of New Product Development, 3rd ed. Somerset, NJ, USA: Wiley, 2012.

[50] L. Kester, A. Griffin, E. J. Hultink, and K. Lauche, "Exploring portfolio decision-making processes," J. Product Innov. Manage., vol. 28, no. 5, pp. 641-661, 2011.

[51] D. N. P. Murthy and W. R. Blischke, "Strategic warranty management-A life cycle approach," IEEE Trans. Eng. Manage., vol. 47, no. 1, pp. 40-54, Feb. 2000.

[52] L. Gorchels, "Transitioning from engineering to product management," Eng. Manage. J., vol. 15, no. 4, pp. 40-47, 2003.

[53] R. G. Cooper, S. J. Edgett, and E. J. Kleinschmidt, "Portfolio management in new product development: Lessons from the leaders-II," Res. Technol. Manage., vol. 40, no. 6, pp. 43-52, 1997.

[54] C. Urhahn and P. Spieth, "Governing the portfolio management process for product innovation - a quantitative analysis on the relationship between portfolio management governance, portfolio innovativeness, and firm performance," IEEE Trans. Eng. Manage., vol. 61, no. 3, pp. 522-533, Aug. 2014

[55] S. Haines, The Product Manager's Desk Reference, 2nd ed. New York, NY, USA: McGraw-Hill, 2014.

[56] R. W. Seifert, J. Tancrez, and I. Bicer, "Dynamic product portfolio management with life-cycle considerations," Int. J. Prod. Econ., vol. 171, pp. 71-83, 2016.

[57] T. J. Housel and A. H. Bell, Measuring and Managing Knowledge. Boston, MA, USA: McGraw-Hill, 2001.

[58] D. Jonas, A. Kock, and H. G. Gemünden, "Predicting project portfolio success by measuring management quality-A longitudinal study," IEEE Trans. Eng. Manage., vol. 60, no. 2, pp. 215-226, May 2013.

[59] R. G. Cooper, "An empirically derived new product project selection model," IEEE Trans. Eng. Manage., vol. EM-28, no. 3, pp. 54-61, Aug. 1981.

[60] F. Langerak and E. J. Hultink, "The impact of new product development acceleration approaches on speed and profitability: Lessons for pioneers and fast followers," IEEE Trans. Eng. Manage., vol. 52, no. 1, pp. 30-42, Feb. 2005.

[61] G. Barczak, A. Griffin, and K. B. Kahn, "Perspective: Trends and drivers of success in NPD practices: Results of the 2003 PDMA best practices study," J. Product Innov. Manage., vol. 26, no. 1, pp. 3-23, 2009.

[62] C. P. Killen, R. A. Hunt, and E. J. Kleinschmidt, "Project portfolio management for product innovation," Int. J. Quality Rel. Manage., vol. 25, no. 1 , pp. 24-38, 2008.

[63] S. Coldrick, P. Longhurst, P. Ivey, and J. Hannis, "An R\&D options selection model for investment decisions," Technovation, vol. 25 , no. 3 , pp. 185-193, 2005.

[64] R. C. McNally, S. S. Durmusoglu, R. J. Calantone, and N. Harmancioglu, "Exploring new product portfolio management decisions: The role of managers' dispositional traits," Ind. Marketing Manage., vol. 38, no. 1, pp. 127-143, 2009.

[65] R. G. Cooper, S. J. Edgett, and E. J. Kleinschmidt, "Best practices for managing R\&D portfolios," Res. Technol. Manage., vol. 41, no. 4, pp. 20 33, 1998.

[66] R. K. Yin, Case Study Research: Design and Methods, 5th ed. Thousand Oaks, CA, USA: Sage, 2013.

[67] A. Bryman and E. Bell, Business Research Methods, 2nd ed. Oxford, U.K. Oxford Univ. Press, 2007.

[68] R. Merton, M. Fiske, and P. Kendall, The Focused Interview: A Manual of Problems and Procedures, 2nd ed. New York, NY, USA: Free Press, 1990.

[69] D. R. Myers, "A practitioner's view: Evolutionary stages of disruptive technologies," IEEE Trans. Eng. Manage., vol. 49, no. 4, pp. 322-329, Nov. 2002 